\title{
Double trouble with acute inferior myocardial infarction and left anterior descending artery thrombi访
}

\author{
Özlem Yıldırımtürk, MD, Assoc Prof, FESC*, Emrah Bozbeyoğlu, MD, Muhammed Keskin, MD, Tolga Onuk, MD, \\ İlhan İlker Avcı, MD, Esra Poyraz, MD, Cevdet Dönmez, MD, Ömer Kozan, MD, Prof
}

Sağlk Bilimleri University, Medical Faculty, Dr. Siyami Ersek Thoracic and Cardiovascular Surgery Training and Research Hospital, Istanbul, Turkey

\section{A R T I C L E I N F O}

\section{Article history:}

Received 26 September 2016

Received in revised form 29 October 2016

Accepted 1 November 2016

Available online 14 November 2016

\begin{abstract}
A B S T R A C T
Concomitant occlusion of multiple epicardial coronary arteries is an uncommon finding in patients presenting with ST-segment elevation myocardial infarction. We reported a 50 years-old male patient who presented with inferior myocardial infarction. Coronary angiography revealed simultaneous occlusion of left anterior descending (LAD) and right coronary artery (RCA). The RCA occlusion treated successfully with percutaneous coronary intervention while LAD occlusion treated with antithrombotic and glycoprotein $2 \mathrm{~B} / 3 \mathrm{~A}$ administration. Although multiple coronary thromboses of coronary arteries in the course of myocardial infarction is uncommon, it is crucial to determine proper treatment for these patients.

(C) 2016 The Society of Cardiovascular Academy. Production and hosting by Elsevier B.V. All rights reserved. This is an open access article under the CC BY-NC-ND license (http://creativecommons.org/licenses/by-nc-nd/4.0/).
\end{abstract}

\section{Introduction}

Acute myocardial infarction (AMI) is caused by disruption of atheromatous plaques and thrombus formation followed by partial or complete occlusion of the epicardial coronary arteries. Multiple ruptured plaques with thrombus formation have been shown in autopsies of $>10 \%$ of individuals with atherosclerosis who died due to non-cardiac etiologies. Conversely, thrombi are frequently observed at sites other than those of the major culprit lesions in patients died subsequent to acute coronary syndromes. ${ }^{1}$ Autopsy series showed thrombotic coronary occlusion of $>1$ major epicardial artery can be as common as $50 \%$ in patients suffering from sudden cardiac death following AMI, this phenomenon is only seen $2.5 \%$ of AMI patients undergoing primary percutaneous coronary intervention (PPCI). ${ }^{2,3}$

\section{Case report}

A 47 years old man with a previous history of smoking, acute coronary syndrome and percutaneous coronary intervention admitted to our emergency unit with sternal pain for $2 \mathrm{~h}$. He was hemodynamically stable, his vital signs showed a regular heart rate of 100 beats/min, blood pressure of 131/90 mm Hg and no respiratory distress. Cardiac

\footnotetext{
t5 Peer review under responsibility of The Society of Cardiovascular Academy.

* Corresponding author at: Sağlık Bilimleri University, Medical Faculty, Dr. Siyami Ersek Thoracic and Cardiovascular Surgery Training and Research Hospital, Tibbiye cad. No:13 Üsküdar, Istanbul, Turkey.

E-mail address: ozlemyt@gmail.com (Ö. Yıldırımtürk).

Peer review under responsibility of The Society of Cardiovascular Academy.
}

auscultation revealed decrease in the intensity of first heart sound. The electrocardiography on arrival revealed sinus rhythm and ST- segment elevation in leads II, III, and aVF (Fig. 1A). Patient received antithrombotic medication prior to primary percutaneous coronary intervention. Coronary angiography showed total occlusion of right coronary artery (RCA) and subtotal occlusion of left anterior descending artery (LAD) with a fresh thrombus (TIMI thrombus grade 4). The RCA lesion was crossed using guidewire and subsequent predilatation performed with $2.0 \times 15 \mathrm{~mm}$ complaint balloon (Invader PTCA, Alvimedica, Assen, Netherlands). This was followed by $3.5 \times 32 \mathrm{~mm}$ bare metal stent (BMS) (Ephosos, Nemed Lxtd, Istanbul, Turkey) implantation and achieved good angiographic result with TIMI-3 flow (Fig. 2). Although the patient had TIMI-3 flow in LAD, following the engagement of left main coronary artery by left judkins guiding catheter, intracoronary tirofiban bolus dose (Irokocardio International, SARL, Geneva) was administered according to the patient's body weight. The LAD patency continued with a TIMI-3 flow and good myocardial blushing (Fig. 3A). Tirofiban maintenance dose completed over $24 \mathrm{~h}$ in the intensive cardiac care unit (ICCU). Addition to tirofiban infusion patient was administered antithrombotic and low molecular weight heparin. Patient had no angina during the ICCU follow-up and ECG showed no changes other than T wave inversion in leads DII, DIII and aVF (Fig. 1B). Patient had no history of hypercoagulopathy states like malignancy or essential thrombocytosis. He also had no history of using amphetamine, cocaine or homeopathic/herbal drugs recently. Transthoracic echocardiography revealed mild hypokinesia in inferior segments with a left ventricular ejection fraction of $45 \%$ and mild degree of mitral regurgitation. Following 24th hours, control coronary angiography showed reduced coronary thrombus burden (Fig. 3B). After $72 \mathrm{~h}$, another coronary angiography 
A

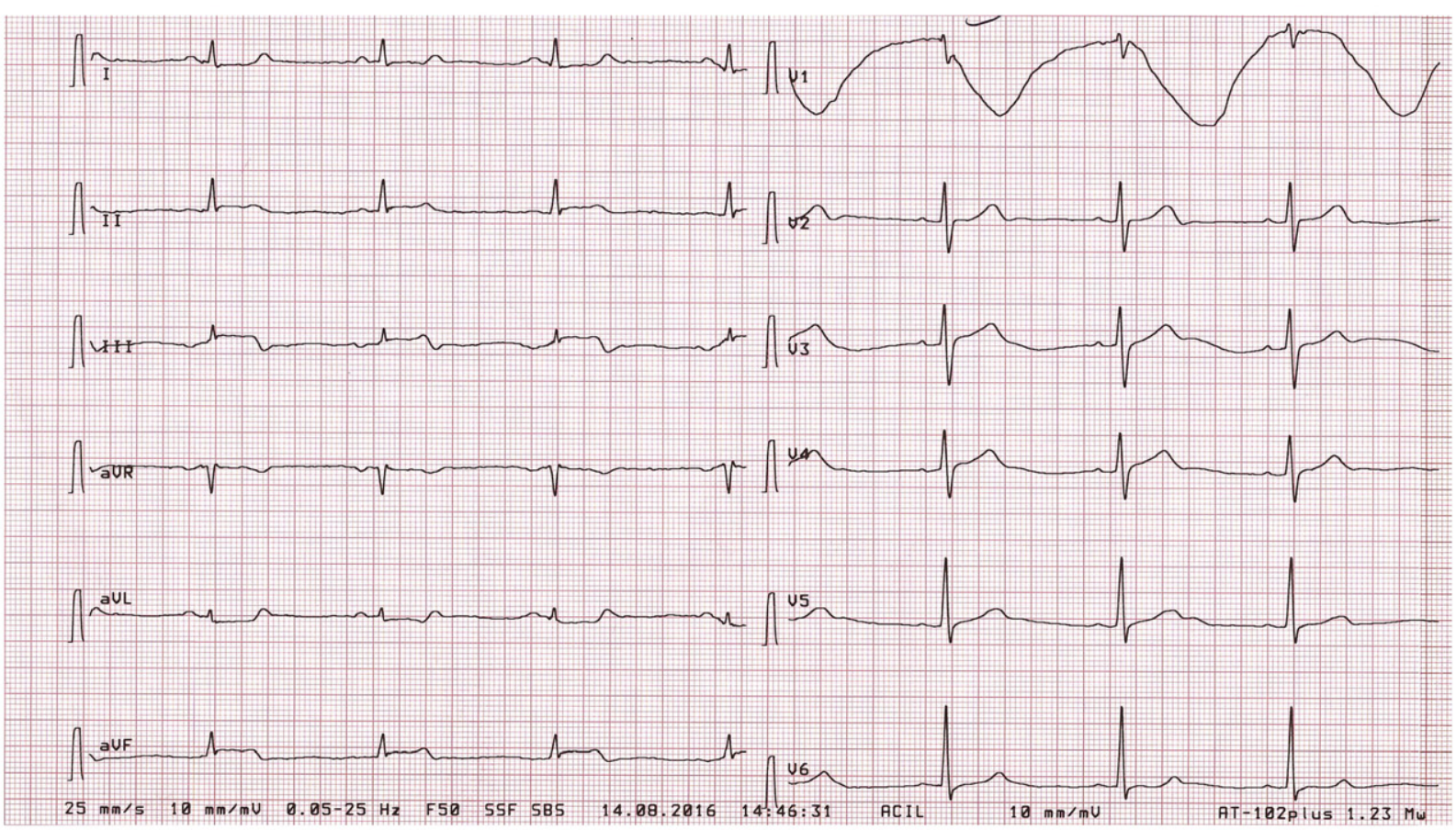

B

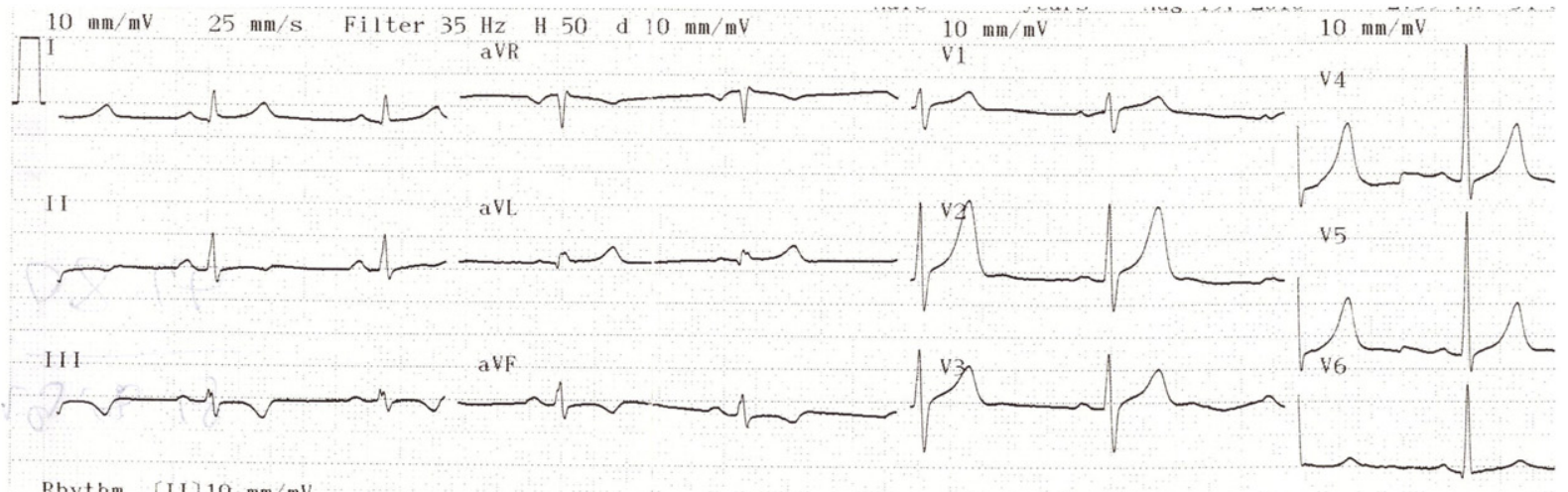

Rhythm [II] $10 \mathrm{~mm} / \mathrm{mV}$

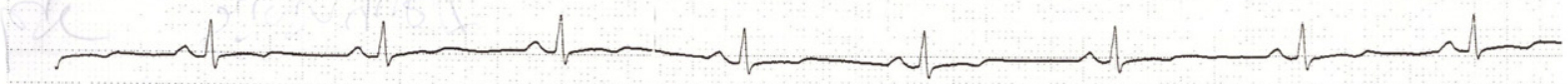

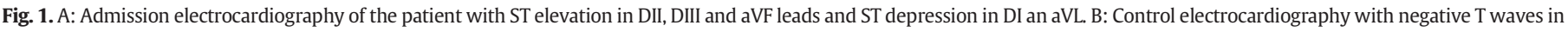
DII, DIII and aVF.

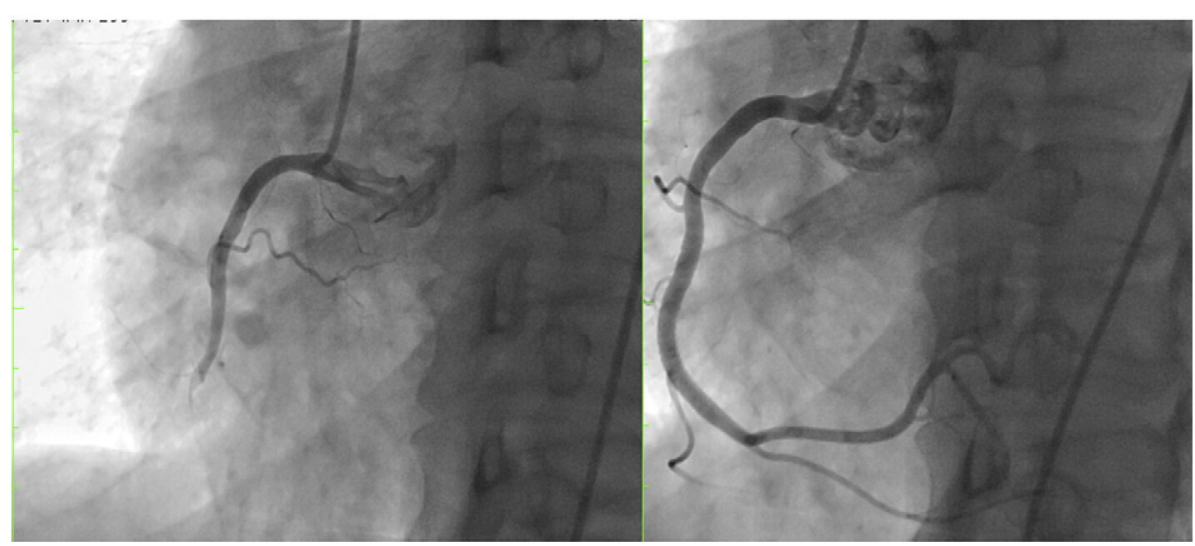

Fig. 2. Right coronary artery before and after primary percutaneous coronary intervention. 


\section{A}

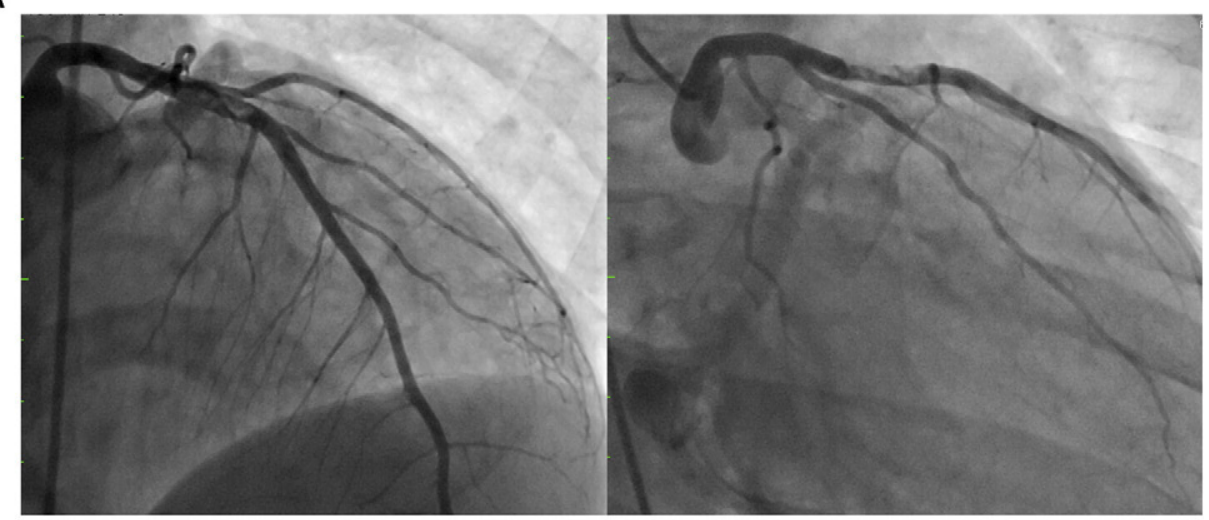

B

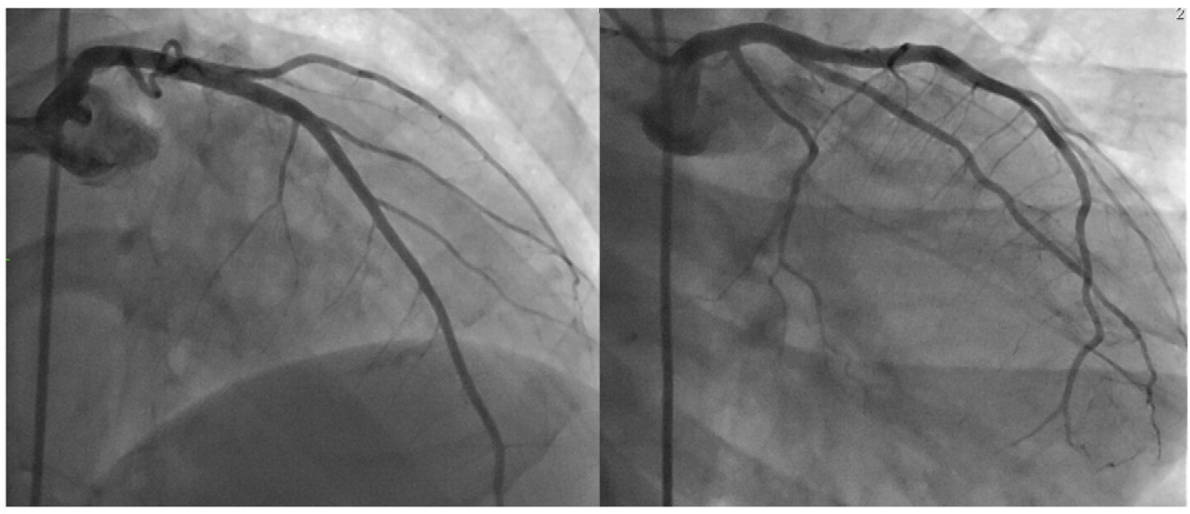

C

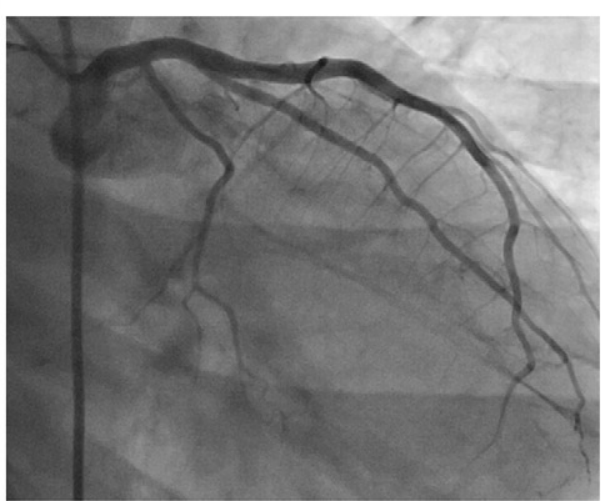

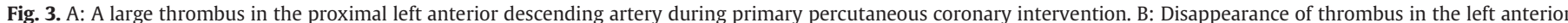
descending artery in control coronary angiogram.

performed to evaluate coronary thrombus on LAD and no thrombus was observed (Fig. 3C). Patient recovered in a short period and discharged with no symptoms.

\section{Discussion}

In this case report, we presented a patient presented with concomitant occlusion of LAD and RCA resulting in acute inferior myocardial infarction. Glycoprotein 2B/3A infusion following primary PCI for RCA resulted in excellent recovery.

Loss of integrity in coronary atheromatous plaques with a subsequent thrombotic occlusion is the main pathological finding in AMI. Coronary artery stenosis in multiple coronary arteries may be commonly seen in patients undergoing PPCI. However, AMI with more than one epicardial coronary artery thrombosis is an infrequent clinical and angiographic finding. The pathophysiology of multiple coronary artery thrombosis is unclear. Existence of additional unstable plaques formations other than culprit lesion has been shown in $21 \%$ of patients with $\mathrm{AMI}^{4}{ }^{4}$ Therefore, widespread plaque instability in all coronary arteries can predispose to multiple coronary thromboses. Previous case reports also suggested that cocaine use, hypercoagulable state and essential thrombocytosis ${ }^{5}$ can be held responsible for multiple coronary thromboses. The etiology of multivessel thrombosis should be evaluated with further studies.

Multiple coronary thromboses are usually reported in patients with fatal arrhythmias, acute pulmonary edema and cardiogenic shock. In our case, patient was normotensive with no additional clinical symptoms, probably due to distal TIMI flow of LAD. The incidence of double-vessel coronary thrombosis may account $1.7-4.8 \%$ of all PPCI patients. According to the review by Kanei, et al., patients with multiple coronary thromboses had common risk factors including essential thrombocytosis, intravenous cocaine abuse, diabetes mellitus and 
smoking. LAD and RCA was involved in $78 \%$ and $87 \%$ of patients ${ }^{6}$ respectively. In our patient the only risk factor was smoking and thrombotic lesions were in both LAD and RCA.

The optimal management strategy in patients with large coronary thrombus is challenging. The presence of intracoronary thrombus may lead to macro and micro distal embolizations, which causes reduced benefit of PPCI. ${ }^{7}$ Pharmacological agents like glycoprotein 2B/3A inhibitors used as an upstream therapy adjunctive to PPCI to reduce thrombus burden and improve microvascular flow. ${ }^{8}$ In recently published EROSION study, 60 patients with the diagnosis of acute coronary syndrome whose coronary angiography revealed stenosis less than $70 \%$ were treated with antithrombotic agents without stenting. ${ }^{9}$ Patients were treated with antithrombotic agents following detection of plaque erosion by OCT. One third of the patients had no thrombus following antithrombotic treatment. Authors concluded that this could be a treatment option for acute coronary syndrome patients.

\section{Conclusion}

Simultaneous thrombosis of coronary arteries in the course of AMI is an uncommon entity that is usually clinically accompanied by cardiogenic shock. Management of these patients should be individualized and the invasive approach should not be considered as the only treatment option.

\section{References}

1. Crea F1, Liuzzo G. Pathogenesis of acute coronary syndromes. J Am Coll Cardiol 2013;61(1):1-11.

2. Ong P, Athanasiadis A, Borgulya G, et al. 3-year follow-up of patients with coronary artery spasm as cause of acute coronary syndrome: the CASPAR (coronary artery spasm in patients with acute coronary syndrome) study follow-up. J Am Coll Cardiol 2011:57(2):147-152

3. Pollak PM, Parikh SV, Kizilgul M, et al. Multiple Culprit Arteries in Patients With ST Segment Elevation Myocardial Infarction Referred for Primary Percutaneous Coronary Intervention. Am J Cardiol 2009;104(5):619-623.

4. Goldstein JA, Demetriou D, Grines CL, et al. Multiple complex coronary plaques in patients with acute myocardial infarction. N Engl J Med 2000;343(13):915-922.

5. Ahmed M, Abdul A. Simultaneous double coronary thrombosis in a 47-year-old male patient with acute myocardial infarction. Am J Case Rep 2013;14:430-434.

6. Kanei Y, Janardhanan R, Fox JT, et al. Multivessel coronary artery thrombosis. J Invasive Cardiol 2009;21(2):66-68.

7. Henriques JP, Zijlstra F, Ottervanger JP, et al. Incidence and clinical significance of distal embolization during primary angioplasty for acute myocardial infarction. Eur Heart J 2002;23(14):1112-1117.

8. Vecchio S, Varani E, Chechi T, et al. Coronary thrombus in patients undergoing primary PCI for STEMI: prognostic significance and management. World J Cardiol 2014;6(6): 381-392.

9. Jia H, Dai J, Xing L, et al. Effective anti-thrombotic therapy without stenting: intravascular optical coherence tomography-based management in plaque erosion the EROSION study). Eur Heart J 2016 Aug 30 Pii: ehw381 [Epun ahead of print]. 